www.nature.com/ja

\title{
Phytotoxic $\alpha$-pyrones produced by Pestalotiopsis guepinii, the causal agent of hazelnut twig blight
}

\author{
Antonio Evidente ${ }^{1}$, Maria Chiara Zonno ${ }^{2}$, Anna Andolf ${ }^{1}$, Ciro Troise ${ }^{1}$, Alessio Cimmino ${ }^{1}$ and \\ Maurizio Vurro ${ }^{2}$
}

The Journal of Antibiotics (2012) 65, 203-206; doi:10.1038/ja.2011.134; published online 1 February 2012

Keywords: 6-(1-hydroxypentyl)-4-methoxy-pyran-2-one; 6-pentyl-4-methoxy-pyran-2-one; Pestalotiopsis guepinii; phytotoxins; $\alpha$-pyrones; twig blight of hazelnut

Pestalotiopsis guepinii (Desm.) is the fungal causal agent of the so-called 'twig blight', one of the most serious diseases of hazelnut (Corylus avellana L.) in Turkey, and one of the main causes of yield losses. P. guepinii has been also isolated from walnut (Juglans spp.) and gum mastic tree (Pistacia lentiscus var. Chia). Recently, the main lipophilic phytotoxic metabolite produced by $P$. guepinii in vitro culture was isolated and identified by spectroscopic methods as pestalopyrone $(7),{ }^{1}$ a pentaketide already known as a minor toxin produced by Pestalotiopsis oenotherae. ${ }^{2}$

When the fungus was grown on a different culture medium, ${ }^{3}$ some fractions obtained by the purification of the culture filtrate, not containing pestalopyrone, proved to be phytotoxic. Their further purification yielded other two amorphous phytotoxic metabolites (1 and 6, Figure 1) that by preliminary spectroscopic experiments (including ${ }^{1} \mathrm{H}$ and ${ }^{13} \mathrm{C}$ NMR, IR and UV) appeared to be closely related to $\alpha$-pyrones.

Indeed 1 was identified as 6-(1-hydroxypentyl)-4-methoxy-pyran2-one and showed optical rotation, IR, UV, ${ }^{1} \mathrm{H}$ and ${ }^{13} \mathrm{C}$ NMR spectra very similar to those previously reported in literature for the metabolite named PC-2 isolated from a Penicillium sp.,5 The same $\alpha$-pyrone (1) was successively isolated also from Galiella rufa together with (-)-gallielactone and its biogenetic precursor. ${ }^{6}$ Penicillium nordicum, P. olsonii and P. verrucosum ${ }^{7}$ and recently a marine-derived fungus Xylaria sp. PSU-F $100^{8}$ also showed to produce 1 . The structure assigned to 1 was supported by the data observed in its COSY, HSQC and HMBC spectra (Table 1) as well as also by the data of the ESIMS. Beside both sodium clusters of the dimmer and the toxin itself, and the pseudomolecular ion observed at $\mathrm{m} / z$ $447[2 \mathrm{XM}+\mathrm{Na}]+, 235$ $[\mathrm{M}+\mathrm{Na}]^{+}, 213[\mathrm{M}+\mathrm{H}]^{+}$, the ESIMS spectrum also showed the significant fragmentation peak $\left[\mathrm{M}+\mathrm{Na}-\mathrm{CO}_{2}\right]^{+}$at $\mathrm{m} / z 191$ generated from the sodium cluster by loss of $\mathrm{CO}_{2}$, which is a fragmentation mechanism typical of $\alpha$-pyrones. ${ }^{9}$ The structure assigned to $\mathbf{1}$ was also supported by the data of its NOESY spectrum in which a significant coupling was observed between the two $\alpha$-pyrone protons H-5 and $\mathrm{H}-3$ and the methoxy group; furthermore, $\mathrm{H}-5$ also coupled with the greater part $\left(\mathrm{H}_{2}-\mathrm{1}^{\prime}, \mathrm{H}_{2}-2^{\prime}\right.$ and $\left.\mathrm{H}_{2}-3^{\prime}\right)$ of the 1-hydroxypentyl side chain protons and these latter themselves coupled.

Some key derivatives were prepared by converting 1 into the corresponding monoacetyl and oxidized derivatives ( 2 and $\mathbf{3}$, respectively, Figure 1), whose spectroscopic data were fully consistent with those previously reported in literature. Indeed, 2 showed optical rotation IR, UV and ${ }^{1} \mathrm{H}$ NMR spectra very similar to those previously reported when PC2 was acetylated by a similar procedure. ${ }^{4}$ The ESIMS spectrum of 2 showed, beside the sodium cluster and the pseudomolecular ion at $\mathrm{m} / z 277[\mathrm{M}+\mathrm{Na}]+, 255[\mathrm{M}+\mathrm{H}]+$, the significant fragmentation peak at $m / z 195[\mathrm{M}+\mathrm{H}-\mathrm{AcOH}]+$, which was generated by the pseudomolecular ion through the typical loss of the acetic acid residue. ${ }^{9}$ The oxidized derivative of 3 showed IR, UV and ${ }^{1} \mathrm{H}$ NMR data very similar to those previously reported in the literature for the product obtained by the reaction of N-bromosuccinimide with the 5-hydroxy-3-methoxy-6-oxo-2-decenoic acid $\delta$-lactone, a metabolite isolated from an unidentified fungus ${ }^{10}$ and close related to the monosubstituted 5,6-dihydro- $\alpha$-pyrone pestalotin. This latter compound is a fungal metabolite with giberellin synergistic activity isolated originally from the phytopathogenic fungus Pestalotia cryptomeriaecola ${ }^{11,12}$ and successively from a Penicillum sp. and designed LL-P880 $\alpha^{4,13}$ Some closely related $\alpha$-pyrones and 5,6- $\alpha$-dihydropyrone were isolated from the same two fungi ${ }^{4,5}$ and also from Penicillium citro-viride. $^{7}$

The absolute stereochemistry of the secondary hydroxylated carbon C-1' of 1-hydroxypentyl side chain at C-6 of 1 was determined by applying the modified Mosher's method. ${ }^{14}$ By reaction with the

${ }^{1}$ Dipartimento di Scienze del Suolo, della Pianta, dell'Ambiente e delle Produzioni Animali, Università di Napoli Federico II, Portici, Italy and ${ }^{2}$ Istituto di Scienze delle Produzioni Alimentari, CNR, Bari, Italy

Correspondence: Professor A Evidente, Dipartimento di Scienze del Suolo, della Pianta, dell'Ambiente e delle Produzioni Animali, Università di Napoli Federico II, via Università 100,80055 Portici, Italy.

E-mail: evidente@unina.it

Received 14 September 2011; revised 21 November 2011; accepted 8 December 2011; published online 1 February 2012 
$R$-(-)- $\alpha$-methoxy- $\alpha$-trifluoromethyl- $\alpha$-phenylacetate (MTPA) and $S$-(+)MTPA chlorides, 1 A was converted in the corresponding diastereomeric $S$-MTPA and R-MTPA esters (4 and 5, respectively), whose spectroscopic data were consistent with the structure assigned to 1 . The comparison between the ${ }^{1} \mathrm{H}$ NMR data (Table 1) of the $S$-MTPA ester (4) and those of the R-MTPA ester (5) of $\mathbf{1}$ allowed to assign to $C-1^{\prime}$ a $R$-configuration. This unambiguously and directly assigned absolute configuration, which allowed to formulate $\mathbf{1}$ as 6-(1R-hydroxypentyl)-4-methoxy-pyran-2-one, was the same of that of metabolite PC-2, which was previously indirectly determined. ${ }^{6}$<smiles></smiles>

$$
\begin{array}{ll}
1 & \mathrm{R}_{1}=\mathrm{H}, \mathrm{R}_{2}=\mathrm{OH} \\
2 & \mathrm{R}_{1}=\mathrm{H}, \mathrm{R}_{2}=\mathrm{OAC} \\
3 & \mathrm{R}_{1}+\mathrm{R}_{2}=\mathrm{O}
\end{array}
$$<smiles>CCCC[C@H](OC(=O)[C@@](C)(c1ccccc1)C(F)(F)F)c1cc(OC)cc(=O)o1</smiles>

4<smiles>CCCC[CH]c1cc(OC)cc(=O)o1</smiles><smiles>CCCC[C@H](OC(=O)[C@@](OC)(c1ccccc1)C(F)(F)F)c1cc(OC)cc(=O)o1</smiles>

5<smiles>[Z]C(=CC)c1cc(OC)cc(=O)o1</smiles>

Figure 1 Structures of 6-(1-hydroxypentyl)-4-methoxy-pyran-2-one and 6pentyl-4-methoxy-pyran-2-one (1 and 6), four derivatives (2-5) of 1 , and pestalopyrone (7).
The $\alpha$-pyrone 6 was identified as 6-pentyl-4-methoxy-pyran-2-one on the basis of its spectroscopic data below described in detail. Although 6 was originally reported as a synthetic compound ${ }^{15}$ in a work aimed at preparing natural polyketides, and as a metabolite of Galiella rufa, no spectroscopic data had been reported for this compound. Its ${ }^{1} \mathrm{H}$ and ${ }^{13} \mathrm{C}$ NMR data (Table 2) were very similar to those of 1, as they differed only for the absence of any secondary hydroxylated carbons in the side chain at C-6. The assignment of the chemical shift to all carbons and corresponding protons was also based on the coupling observed in the COSY, HSQC and HMBC spectra. In the NOESY spectrum a significant coupling was observed between the methoxy group with both two $\alpha$-pyrone protons $\mathrm{H}-5$ and $\mathrm{H}-3$ with, as well as $\mathrm{H}-5$ also coupled with the greater part $\left(\mathrm{H}_{2}-1^{\prime}\right.$, $\mathrm{H}_{2}-2^{\prime}$ and $\left.\mathrm{H}_{2}-3^{\prime}\right)$ of the $n$-pentyl side chain protons and these latter themselves coupled. This structure of $\mathbf{6}$ was also supported by ESIMS data, which showed the sodium cluster and the pseudomolecular ion at $m / z 219[\mathrm{M}+\mathrm{Na}]^{+}$and $197[\mathrm{M}+\mathrm{H}]^{+}$, respectively.

No biological properties were reported for $\alpha$-pyrones 1 and 6 except some bioassays carried out on the metabolite $\mathbf{6}$ for a possible nematocidal activity, ${ }^{16,17}$ but with negative evidences. For this reason,

Table $2{ }^{1} \mathrm{H}$ and ${ }^{13} \mathrm{C}$ NMR data of 6-pentyl-4-methoxy-pyran-2-one $(6)^{\mathrm{a}, \mathrm{b}}$

\begin{tabular}{lccc}
\hline$C$ & $\delta_{C} m^{c}$ & $\delta_{H}$ & $H M B C$ \\
\hline 2 & $164.3 \mathrm{~s}$ & & $\mathrm{H}-3$ \\
3 & $87.3 \mathrm{~d}$ & $5.43 \mathrm{~d}(\mathrm{~J}=2.2 \mathrm{~Hz})$ & \\
4 & $170.9 \mathrm{~s}$ & & $\mathrm{H}-5, \mathrm{H}-3, \mathrm{OMe}$ \\
5 & $100.0 \mathrm{~d}$ & $5.79 \mathrm{~d}(\mathrm{~J}=2.2 \mathrm{~Hz})$ & $\mathrm{H}_{2}-1^{\prime}$ \\
6 & $165.1 \mathrm{~s}$ & & $\mathrm{H}-5, \mathrm{H}_{2}-1^{\prime}, \mathrm{H}_{2}-2^{\prime}$ \\
$1^{\prime}$ & $32.7 \mathrm{t}$ & $2.46 \mathrm{t}(\mathrm{J}=7.5 \mathrm{~Hz})$ & $\mathrm{H}_{2}-2^{\prime}, \mathrm{H}_{2}-3^{\prime}, \mathrm{Me}-4^{\prime}$ \\
$2^{\prime}$ & $25.9 \mathrm{t}$ & $1.67(2 \mathrm{H}) \mathrm{m}$ & $\mathrm{H}_{2}-1^{\prime}$ \\
$3^{\prime}$ & $22.0 \mathrm{t}$ & $1.34(2 \mathrm{H}) \mathrm{m}$ & $\mathrm{H}_{2}-2^{\prime}, \mathrm{Me}-4^{\prime}$ \\
$4^{\prime}$ & $30.0 \mathrm{t}$ & $1.34(2 \mathrm{H}) \mathrm{m}$ & \\
$5^{\prime}$ & $14.2 \mathrm{q}$ & $0.92(3 \mathrm{H}) \mathrm{t}(\mathrm{J}=6.8 \mathrm{~Hz})$ & \\
OMe & $57.1 \mathrm{q}$ & $3.82 \mathrm{~s}$ &
\end{tabular}

aThe chemical shifts are in $\delta$ values (p.p.m.) from TMS

${ }^{b} 2 D^{1} \mathrm{H},{ }^{1} \mathrm{H}(\mathrm{COSY}){ }^{13} \mathrm{C},{ }^{1} \mathrm{H}$ (HSQC) NMR experiments delineated the correlations of all the protons and the corresponding carbons.

\begin{tabular}{|c|c|c|c|c|}
\hline & 1 & & 4 & 5 \\
\hline Position & $\delta_{H}$ & HMBC & $\delta_{H}$ & $\delta_{H}$ \\
\hline 2 & & $\mathrm{H}-3$ & & \\
\hline 3 & $5.43 \mathrm{~d}(J=2.1 \mathrm{~Hz})$ & $\mathrm{H}-5, \mathrm{OMe}$ & $5.450 \mathrm{~d}(J=2.0 \mathrm{~Hz})$ & $5.480 \mathrm{~d}(J=2.0 \mathrm{~Hz})$ \\
\hline 4 & & $\mathrm{H}-5, \mathrm{H}-3, \mathrm{OMe}$ & & \\
\hline 5 & $6.07 \mathrm{~d}(J=2.1 \mathrm{~Hz})$ & $\mathrm{H}-3, \mathrm{H}-\mathrm{1}^{\prime}$ & $5.805 \mathrm{~d}(J=2.0 \mathrm{~Hz})$ & $5.981 \mathrm{t}(\mathrm{J}=6.5 \mathrm{~Hz})$ \\
\hline 6 & & $\mathrm{H}-5, \mathrm{H}-1^{\prime}$ & & \\
\hline $1^{\prime}$ & $4.38 \mathrm{dd}(J=7.8$ and $4.7 \mathrm{~Hz})$ & $\mathrm{H}-5, \mathrm{H}_{2}-2^{\prime}, \mathrm{H}_{2}-3^{\prime}$ & $5.610 \mathrm{t}(J=6.3 \mathrm{~Hz})$ & $5.630 \mathrm{t}(J=6.5 \mathrm{~Hz})$ \\
\hline $2^{\prime}$ & $\begin{array}{l}1.86 \mathrm{~m} \\
1.71 \mathrm{~m}\end{array}$ & $\mathrm{H}-1^{\prime}, \mathrm{H}_{2}-3^{\prime}, \mathrm{Me}-5^{\prime}$ & $1.960(2 \mathrm{H}) \mathrm{m}$ & $1.929(2 \mathrm{H}) \mathrm{m}$ \\
\hline $3^{\prime}$ & $1.35(2 \mathrm{H}) \mathrm{m}$ & $\mathrm{H}-1^{\prime}, \mathrm{H}_{2}-2^{\prime}, \mathrm{Me}-5^{\prime}$ & $1.333(2 \mathrm{H}) \mathrm{m}$ & $1.210(2 \mathrm{H}) \mathrm{m}$ \\
\hline $4^{\prime}$ & $1.35(2 \mathrm{H}) \mathrm{m}$ & $\mathrm{H}-1^{\prime}, \mathrm{H}_{2}-2^{\prime}, \mathrm{H}_{2}-3^{\prime}, \mathrm{Me}-5^{\prime}$ & $1.333(2 \mathrm{H}) \mathrm{m}$ & $1.210(2 \mathrm{H}) \mathrm{m}$ \\
\hline $5^{\prime}$ & $0.90(3 \mathrm{H}) \mathrm{d}(\mathrm{J}=7.0 \mathrm{~Hz})$ & $\mathrm{H}_{2}-3^{\prime}$ & $0.901(3 \mathrm{H}) \mathrm{t}(\mathrm{J}=6.9 \mathrm{~Hz})$ & $0.853(3 \mathrm{H}) \mathrm{t}(\mathrm{J}=7.0 \mathrm{~Hz})$ \\
\hline $\mathrm{MeO}$ & $3.82 \mathrm{~s}$ & & $3.811 \mathrm{~s}$ & $3.828 \mathrm{~s}$ \\
\hline $\mathrm{MeO}$ & & & $3.560 \mathrm{~s}$ & $3.570 \mathrm{~s}$ \\
\hline $\mathrm{Ph}$ & & & $7.530-7.420 \mathrm{~m}$ & $7.550-7.250 \mathrm{~m}$ \\
\hline
\end{tabular}

${ }^{\mathrm{c}}$ Multiplicities were assigned by DEPT spectra.

Table $1{ }^{1}$ H NMR data of 6-(1-hydroxypentyl)-4-methoxy-pyran-2-one (1) $)^{\mathrm{a}, \mathrm{b}}$ its $(S)$ - and $(R)$-MTPA esters $(4 \text { and } 5)^{\mathrm{a}}$

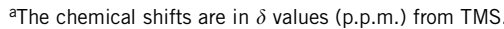

${ }^{b} 2 D^{1} \mathrm{H},{ }^{1} \mathrm{H}(\mathrm{COSY}){ }^{13} \mathrm{C},{ }^{1} \mathrm{H}$ (HSQC) NMR experiments delineated the correlations of all the protons and the corresponding carbons. 
a preliminary assessment of their phytotoxic and antimicrobial activities was performed and compared with those of the two derivatives ( 2 and 3 ) of $\mathbf{1}$. When tested by puncture on leaves of a number of plant species (that is: Convolvulus arvensis, Mercurialis annua, Chenopodium album and Ailanthus altissima) at $20 \mu \mathrm{g}$ per droplet, $\mathbf{1}$ proved to be highly phytotoxic, causing the fast appearance of large necrosis on the leaves of all the species tested. $\mathbf{6}$ proved to be almost as toxic as $\mathbf{1}$, although it was unable to cause necrosis on leaves of C. arvensis, probably owing to a lower sensitivity of this plant. The acetyl derivative 2 was less active compared with 1, whereas the oxidized one 3 proved to be completely ineffective to all the tested leaves. Probably some plants, as C. arvensis and M. annua, have the capability to hydrolyse $\mathbf{3}$ into $\mathbf{1}$. Assayed by comparison at the same concentration, the main metabolite pestalopyrone proved to be on average less toxic then the two $\alpha$-pyrones $\mathbf{1}$ and $\mathbf{6}$. These results make possible to suppose that the $n$-pentyl side chain is important for the activity. If a substituent is present in this side chain it could be a nucleophilic group as are the hydroxy or the double bond present, respectively, in 1 and 7. Conversely, the presence of an electrophilic group, as is the carbonyl present in 3, determines the loss of activity. However, 7 showed a reduced phytotoxicity as a 2-butenyl group instead of a $n$-pentyl side chain was bonded at C-6. In the bioassay on Lemna minor L., carried out at the concentration of $100 \mu \mathrm{g}$ per well the most toxic compounds proved to be 6 and the acetyl derivative of 1 , which caused the complete desiccation of the plantlets already $24 \mathrm{~h}$ after their immersion in the test solution. This effect was similar to that observed in the case of fumonisin B1, a powerful phytotoxin ${ }^{18}$ used for comparison at the same concentration. $\alpha$-Pyrone 1 and its oxidized derivative 3 proved to be less toxic and slower acting, as they caused a clear chlorosis of the plantlets $48 \mathrm{~h}$ after immersion. In this bioassay pestalopyrone proved to be ineffective. None of these compounds, when tested up to $100 \mu \mathrm{g}$ per diskette, showed any antibiotic activities when assayed on Bacillus subtilis (gram + ) and Escherichia coli (gram-), and neither a fungitoxic activity when assayed against Geotrichum candidum.

In conclusion, the two $\alpha$-pyrone, 6 -(1-hydroxypentyl)-4-methoxypyran-2-one; 6-pentyl-4-methoxy-pyran-2-one (1 and 6) were isolated for the first time as metabolites of $P$. guepinii together pestalopyrone, another $\alpha$-pyrone recently isolated from the same fungus. ${ }^{1}$ Pestalopyrone, named demehtyl nectriapyrone A, was previously isolated with nectriapyrone $B$ from an unidentified fungus isolated from the indo-pacific sponge Stylotella sp. ${ }^{19,20}$ Furthermore, a suitable substituted $n$-pentyl side chain at C- 6 of pyrone ring appeared to be a structural feature important for the phytotoxicity.

\section{EXPERIMENTAL PROCEDURE}

Optical rotations were measured in $\mathrm{CHCl}_{3}$ solution on a Jasco P-1010 (Tokyo, Japan) digital polarimeter; IR spectra were recorded as glassy film on a Perkin-Elmer Spectrum (Norwak, CT, USA). One FT-IR Spectrometer and UV spectra were taken in MeCN solution on a Perkin-Elmer Lambda 25 UV/ Vis spectrophotometer. ${ }^{1} \mathrm{H}$ and ${ }^{13} \mathrm{C}$ NMR spectra were recorded at 600 and 400, and 100 and $150 \mathrm{MHz}$, respectively, in $\mathrm{CDCl}_{3}$ on Bruker spectrometers (Kalsruhe, Germany), unless otherwise noted. The same solvent was used as internal standard. Carbon multiplicities were determined by DEPT spectra. DEPT, COSY-45, HSQC, HMBC and NOESY experiments were performed using Bruker microprograms. ESI MS spectra were recorded on Waters Micromass Q-TOF Micro -(Milford, MS, USA) instruments. Analytical and preparative TLC were performed on Si gel (Kieselgel $60 \mathrm{~F}_{254}, 0.25$ and $0.50 \mathrm{~mm}$, respectively, Merck, Darmstadt, Germany) plates; the spots were visualized by exposure to UV light and/or by spraying first with $10 \% \mathrm{H}_{2} \mathrm{SO}_{4}$ in $\mathrm{MeOH}$ and then with $5 \%$ phosphomolybdic acid in $\mathrm{EtOH}$, followed by heating at $110^{\circ} \mathrm{C}$ for $10 \mathrm{~min}$. CC: Si gel (Kieselgel 60, 0.063-0.200 mm, Merck).
Solvent systems: (A) EtOAc- $n$-hexane (3:2); (B) EtOAc- $n$-hexane (1:1); (C) EtOAc- $n$-hexane $(2: 3)$.

The strain of $P$. guepinii used in this study was isolated from naturally diseased hazelnut leaves as previously reported ${ }^{3}$ and deposited in the collection of the Istituto di Scienze delle Produzioni Alimentari, CNR, Bari, Italy, with the number ITEM 13203. The fungus was grown on a mineral defined liquid media named M1-D. ${ }^{5}$ The culture filtrate having high phytotoxic activity on leaves (3.2501, pH 4.80) was lyophilized, resuspended in distilled water (1/10 of its original volume) and then extracted by EtOAc (four times with $330 \mathrm{ml}$ each). The organic extracts were combined, dried with $\mathrm{Na}_{2} \mathrm{SO}_{4}$ and the solvent evaporated under reduced pressure, yielding a brown oil $(141.9 \mathrm{mg})$. This oil was purified by column chromatography (solvent system A), yielding seven groups of homogeneous fractions. The first three fractions were combined $(11.0 \mathrm{mg}$ ) and further purified by TLC (solvent system B). Three metabolites were obtained as amorphous solids; that is: the already described pestalopyrone (7) (4.3 mg, $\left.R_{f} 0.28\right) ; 6$-(1-hydroxypentyl)-4-methoxy-pyran-2-one (1, $1.9 \mathrm{mg}$, $\left.0.6 \mathrm{mgl}^{-1}, \quad R_{f} \quad 0.57\right)$; and 6-pentyl-4-methoxy-pyran-2-one $(6,1.7 \mathrm{mg}$, $\left.0.5 \mathrm{mgl}^{-1}, R_{f} 0.49\right)$. The fourth fraction $(8.0 \mathrm{mg})$ was also purified by TLC (solvent system A) giving a further amount of $1 \mathrm{~A}(6.4 \mathrm{mg}$, total $10.7 \mathrm{mg}$, $\left.3.3 \mathrm{mgl}^{-1}\right)$.

6-(1-hydroxypentyl)-4-methoxy-pyran-2-one (1): Amorphous solid; $[\alpha]_{D}^{25}$ +59.8 (c 0.29); IR $v_{\max } 3396,1689,1645,1562,1455,1409 \mathrm{~cm}^{-1}$; UV $\lambda_{\max }$ $281 \mathrm{~nm}\left(\log \varepsilon\right.$ 4.25), $224 \mathrm{~nm}$ (sh); (lit. $4:[\alpha]_{\mathrm{D}}^{23}+78.5(c \quad 1.0 \mathrm{MeOH})$. IR $v^{\text {Film }}{ }_{\text {max }} \mathrm{cm}^{-1}: 3460,1720,1700,1650,1570,1410,1255 . \mathrm{UV}^{\mathrm{EtOH}} \lambda_{\max } \mathrm{nm}(\varepsilon)$ 227 (sh. 3650) 289 (9850), $224 \mathrm{~nm}$ ); ${ }^{1} \mathrm{H}$ NMR see Table $1 ;{ }^{13} \mathrm{C}$ NMR was very similar to that previosly reported in literature; ${ }^{20}$ ESIMS: $m / z 447[2 \mathrm{XM}+\mathrm{Na}]^{+}$, $235[\mathrm{M}+\mathrm{Na}]^{+}, 213[\mathrm{M}+\mathrm{H}]^{+}, 191\left[\mathrm{M}+\mathrm{Na}-\mathrm{CO}_{2}\right]^{+}$.

6-pentyl-4-methoxy-pyran-2-one (6): Amorphous solid; IR $v_{\max }$ 1725, 1649, $1569,1456,1411 \mathrm{~cm}^{-1} ; \mathrm{UV} \lambda_{\max } 282 \mathrm{~nm}(\log \varepsilon 3.37), 224 \mathrm{~nm}(\mathrm{sh}) ;{ }^{1} \mathrm{H}$ and ${ }^{13} \mathrm{C}$ NMR spectra: see Table 2; ESIMS (+) $m / z 219[\mathrm{M}+\mathrm{Na}]^{+}, 197[\mathrm{M}+\mathrm{H}]^{+}$.

1'-O-Acetyl derivative of 1 (2): 6-(1-hydroxypentyl)-4-methoxy-pyran-2one $(1,3.7 \mathrm{mg})$ was converted into the corresponding $1-\mathrm{O}^{\prime}$-acetyl derivative by usual reaction with pyridine and acetic anhydride. Derivative 2 had: $[\alpha]_{D}^{25}+61.3$ (c 0.24); IR $v_{\max } 1731,1655,1572,1455,1412,1225 \mathrm{~cm}^{-1}$; UV $\lambda_{\max } 282 \mathrm{~nm}$

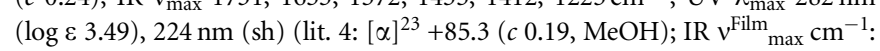
$1730,1650,1565,1405,1245,1225,1035,1020) ;{ }^{1} \mathrm{H}$ NMR, $\delta 5.97(1 \mathrm{H}, \mathrm{d}$, $J=2.1 \mathrm{~Hz}, \mathrm{H}-5), 5.47(1 \mathrm{H}, \mathrm{d}, J=2.1 \mathrm{~Hz}, \mathrm{H}-3), 5.44(1 \mathrm{H}, \mathrm{dd}, J=7.3$ and $6.0 \mathrm{~Hz}$, $\left.\mathrm{H}-1^{\prime}\right), 3.82(3 \mathrm{H}, \mathrm{s}, \mathrm{OMe}), 2.14(3 \mathrm{H}, \mathrm{s}, \mathrm{MeCO}), 1.89\left(\mathrm{~m}, \mathrm{H}_{2}-2^{\prime}\right), 1.34(4 \mathrm{H}, \mathrm{m}$, $\mathrm{H}_{2}-3^{\prime}$ and $\left.\mathrm{H}_{2}-4^{\prime}\right), 0.93\left(3 \mathrm{H}, \mathrm{t}, J=6.9 \mathrm{Me}-5^{\prime}\right)$. EIMS (rel. int) $m / z: 277[\mathrm{M}+\mathrm{Na}]^{+}$, $255[\mathrm{M}+\mathrm{H}]^{+}, 195[\mathrm{M}+\mathrm{H}-\mathrm{AcOH}]^{+}$.

1-Oxo-derivative of 1 (3): 6-(1-hydroxypentyl)-4-methoxy-pyran-2-one (1, $2.0 \mathrm{mg}$ ) was oxidized at room temperature in anhydrous $\mathrm{CH}_{2} \mathrm{Cl}_{2}$ with $\mathrm{MnO}_{2}$ $(24.6 \mathrm{mg})$. Derivative 3, obtained as homogeneous solid (1.1 mg) had: IR $v_{\max }$ $1721,1699,1637,1567,1465,1412 \mathrm{~cm}^{-1}$; UV $\lambda_{\max } 310 \mathrm{~nm}(\log \varepsilon 3.29), 220 \mathrm{~nm}$ ( $\log \varepsilon$ 3.86) (lit. 10: i.r. (KBr) 1721, 1702, 1639, 1569, 1273 and $1257 \mathrm{~cm}^{-1}$; $\left(\mathrm{CCl}_{4}\right) 1746,1711,1638$ and $1247 \mathrm{~cm}^{-1}$; uv $\lambda \max (\mathrm{EtOH}) 223(\varepsilon 18100)$ and $309 \mathrm{~nm}\left(\varepsilon\right.$ 5350)). ${ }^{1} \mathrm{H}$ NMR, $\delta 6.78(1 \mathrm{H}, \mathrm{d}, J=2.3 \mathrm{~Hz}, \mathrm{H}-5), 5.73(1 \mathrm{H}, \mathrm{d}$, $J=2.3 \mathrm{~Hz}, \mathrm{H}-3), 3.88(3 \mathrm{H}, \mathrm{s}, \mathrm{OMe}) 2.92\left(2 \mathrm{H}, \mathrm{t}, J=7.4 \mathrm{~Hz}, \mathrm{H}_{2}-2^{\prime}\right), 1.64-130$. $\left(4 \mathrm{H}, \mathrm{m}, \mathrm{H}_{2}-3\right.$ and $\left.\mathrm{H}_{2}-4^{\prime}\right), 0.96\left(3 \mathrm{H}, \mathrm{t}, J=7.4 \mathrm{Me}-5^{\prime}\right)$. ESIMS (+) $m / z: 233$ $[\mathrm{M}+\mathrm{Na}]^{+}, 211[\mathrm{M}+\mathrm{H}]^{+}$

(S)- $\alpha$-Methoxy- $\alpha$-trifluoromethyl- $\alpha$-phenylacetate (MTPA) ester of $\alpha$-pyrone 1 (4). 6-(1-hydroxypentyl)-4-methoxy-pyran-2-one (1, 2.6 mg) was converted into the corresponding $\alpha$-Methoxy- $\alpha$-trifluoromethyl $\alpha$-phenylacetate (MTPA) ester of $\alpha$-pyrone 1 (4) by reaction with (R)-(-)-MPTA-Cl dry pyridine. The usual work-up of the reaction yielded 4 as a homogeneous solid $(2.9 \mathrm{mg})$. It had: $[\alpha]_{25}^{\mathrm{D}}+32.0$ (c 0.26$)$; IR $v_{\max } 1732,1658,1573,1455$, $1413 \mathrm{~cm}^{-1}$; UV $\lambda_{\max } 282 \mathrm{~nm}(\log \varepsilon 3.79) 227 \mathrm{~nm}$ (sh); for ${ }^{1} \mathrm{H}$ NMR, see Table 1; ESIMS $(+) m / z 879[2 \times \mathrm{xM}+\mathrm{Na}]^{+}, 451[\mathrm{M}+\mathrm{Na}]^{+}, 429[\mathrm{M}+\mathrm{H}]^{+}$.

(R)- $\alpha$-Methoxy- $\alpha$-trifluoromethyl- $\alpha$-phenylacetate (MTPA) ester of $\alpha$-pyrone 1 (5). 6-(1-hydroxypentyl)-4-methoxy-pyran-2-one (1, 2.6 mg) was converted into the $(R)-\alpha$-methoxy- $\alpha$-trifluoromethyl- $\alpha$-phenylacetate (MTPA) ester of $\alpha$-pyrone 1 (5) by reaction (S)-(+)-MPTA-Cl. The reaction was carried out under the same conditions used for preparing 4 from 1. 5, obtained as a homogeneous solid $(2.6 \mathrm{mg})$, had: $[\alpha]_{25}^{\mathrm{D}}+60.8$ (c 0.23); IR 1732, 1658, 1573, 1455, 1413, UV $\lambda_{\max } 281 \mathrm{~nm}(\log \varepsilon 3.77) 227 \mathrm{~nm}(\mathrm{sh})$ and ESIMS very similar to those of 4. For ${ }^{1} \mathrm{H}$ NMR, see Table 1; ESIMS (+) $m / z 879[2 \mathrm{xM}+\mathrm{Na}]^{+}, 451$ $[\mathrm{M}+\mathrm{Na}]^{+}, 429[\mathrm{M}+\mathrm{H}]^{+}$. 
The bioassay of culture filtrates, organic extracts, chromatographic fractions and pure compounds were assayed by using a leaf puncture assay on different non-host plants; that is, Convolvulus arvensis, Mercurialis annua, Chenopodium album and Ailanthus altissima. The test solutions were dissolved in a small volume of $\mathrm{MeOH}$ (final concentration of $\mathrm{MeOH}=2 \%$ ) and then diluted with distilled water. The pure compounds were tested at a final concentration of $2 \mathrm{mg} \mathrm{ml}^{-1}$, by applying $10 \mu \mathrm{l}$ of solution to detached leaves previously punctured with a needle. Leaves were kept in a moistened chamber under continuous fluorescent lights. Symptoms were estimated visually 3 days after droplet application, using a score from 0 (no symptoms) to 4 (very wide necrosis $-1 \mathrm{~cm}$ diameter).

Pure compounds were tested at a concentration of $2 \mu \mathrm{g} \mu \mathrm{l}^{-1}$ on Lemna minor by adapting a protocol already described..$^{18}$ Briefly, the wells of sterile, plastic 96-well microtitre plates were filled with $50 \mu \mathrm{l}$ aliquot of solutions containing the metabolites to be tested, at the concentration of above reported. One frond of actively growing axenic $L$. minor was placed into each well. Control wells were included in each plate. At least three replications were prepared for each compound. The plates were incubated in a growth chamber with $12 / 24 \mathrm{~h}$ fluorescent lights and observed daily up to 4 days. One day after the application of the test solution, $100 \mu \mathrm{l}$ of distilled water was added to each well. Appearance of necrotic or chlorotic symptoms was assessed visually by comparison of the treated plants with the control appearance.

The pure compounds were also tested for the antifungal activity on Geotrichum candidum, for the antibiosis against Bacillus subtilis (gram + ) and Escherichia coli (gram-) according to the protocols already described, up to $100 \mu \mathrm{g}$ per diskette. ${ }^{21}$

\section{ACKNOWLEDGEMENTS}

The authors thank Dr Pierluigi Mazzei, Università di Napoli Federico II, for supplying NMR spectra. This work was partially supported by a grant from the Italian Ministry of University and Research (MIUR). Contribution DISSPAPA N. 251. Prof. Antonio Evidente is associated to the Istituto di Chimica Biomolecolare del CNR, Pozzuoli, Italy.

1 Turkann, M. et al. Phytotoxins produced by Pestalotiopsis guepinii, the causal agent of halznut twig blight. Phytopathol. Medit. 50, 154-158 (2011) (and references therein cited).

2 Venkatasubbaiah, P., van Dyke, C. G. \& Chilton, W. S. Phytotoxins produced by Pestalotiopsys oenotherae, a pathogen of evening primrose. Phytochemistry 30, 1471-1474 (1991).
3 Pinkerton, F. \& Strobel, G. Serinol as an activator of toxin production in attenuated cultures of Heminthosporium sacchari. Proc. Natl Acad. Sci. USA 73, 4007-4011 (1976).

4 Kimura, Y., Mcgahren, W. J., Suzuki, A. \& Tamura, S. Structure of a new fungal pyrone from an unidentified Penicillium sp. Agric. Biol. Chem. 42, 1625-1626 (1978).

5 Kimura, Y., Suzuki, A. \& Tamura, S. ${ }^{13} \mathrm{C}$ NMR spectra of pestalotin and its analogues. Agric. Biol. Chem. 44, 451-452 (1980).

6 Köpcke, B., Weber, R. W. S. \& Anke, H. Galiellalactone and ist biogenetic precursor as chemotaxonomic markers of the Sarcosomataceae (Ascomycota). Phytochemistry 60, 709-714 (2002a)

7 Rahbaek, L., Sperry, S., Frisvad, J. C. \& Larsen, T. O. PC-2, LL-P888gamma and some novel analogue alpha-pyrones from Penicillium nordicum, $P$. verrucosum and $P$. olsonii. Biochem. System. Ecol. 31, 313-317 (2003).

8 Rukachaisrikul, V. et al. An [11]cytochalasin derivative from marine-derived fungus Xylaria sp. PSU-F100. Chem. Pharm. Bull. 57, 1409-1411 (2009).

9 Pretsch, E., Bühlmann, P. \& Affolter, C. Structure Determination of Organic Compounds - Tables of Spectral Data 161-239 (Springer-Verlag, Berlin, 2000).

10 Strunz, G. M., Heissner, C. J., Kakushima, M. \& Stillwell, M. A. Metabolites of an unidentified fungus: a new 5,6-dihydro-2-pyrone related topestalotin. Can. J. Chem. 52, 825-826 (1974).

11 Kimura, Y., Katagiri, K. \& Tamura, S. Isolation and biological activity of pestalotin, a giberellin-synergist from Pestalotia cryptomeriaecola. Agric. Biol. Chem. 35, 1313-1314 (1971).

12 Kimura, Y., Katagiri, K. \& Tamura, S. Structure of pestalotin, a new metabolite from Pestalotia cryptomeriaecola. Tetrahedron Lett. 3137-3140 (1971).

13 Ellestad, G. A., MacGahren, W. J. \& Kunstmann, M. P. Structure of a new fungal lactone LL-P880. $\alpha$, from an unidentified Penicillium sp. J. Org. Chem. 37, 2045-2047 (1972).

14 Ohtani, I., Kusumi, T., Kashman, Y. \& Kakisawa, H. New Bioactive Triterpenoids from Melia volkensi. J. Am. Chem. Soc. 113, 4092-4096 (1991).

15 de March, P., Moreno-Manas, M. \& Ripoll, I. Alkylation of position C-5 of triacetic acid lactone by $[2,3]$ sigmatropic rearrangement of sulphonium ylide. Chem. Ber. 120, 1313-1419 (1987).

16 Köpcke, B., Johansson, M., Sterner, O. \& Anke, H. Biologically active secondary metabolites from the Ascomycete A111-95. 1. Production, isolation and biological activities. J. Antibiot. 55, 36-40 (2002).

17 Johansson, M., Köpcke, B., Anke, H. \& Sterner, O. Biologically active secondary metabolites from the Ascomycete A111-95. 2. Structure elucidation activities. J. Antibiot. 55, 104-106 (2002).

18 Vesonder, R. F., Labeda, D. P. \& Peterson, R. E. Phytotoxic activity of selected watersoluble metabolites of Fusarium against Lemna minor L. (Duckweed). Mycopathologia 118, 185-189 (1992).

19 Abrell, L. M., Cheng, X. C. \& Crew, P. New nectriapyrones by salt water cultures of a fungus separated from an indo-pacific sponge. Tetrahedron Lett. 35, 9159-9160 (1994).

20 Kimura, Y., Hamasaki, T. \& Nakajima, H. Streochemistry and biological activities of LL-P880 $\gamma$, a pestalotin analogue, produced by Penicillium citro-viride. Agric. Biol. Chem. 50, 1649-1650 (1986).

21 Bottalico, A., Capasso, R., Evidente, A., Randazzo, G. \& Vurro, M. Cytochalasins: structure-activity relationships. Phytochemistry 29, 93-96 (1990). 